\title{
Limitations of a QRS scoring system to assess left ventricular function and prognosis at hospital discharge after myocardial infarction
}

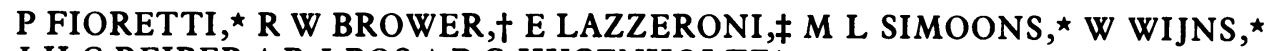

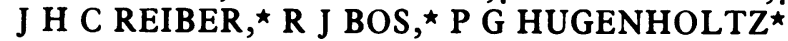

From the $\star$ Thoraxcenter in cooperation with the Department of Nuclear Medicine, Erasmus University and University Hospital Dijkzigt, and the †Interuniversity Cardiology Institute, Rotterdam, The Netherlands; and the $\ddagger$ Division of Cardiology, Ospedale Regionale, Parma, Italy

SUMMARY The value of a QRS scoring system derived from 12 lead electrocardiograms to estimate left ventricular ejection fraction was assessed in a prospective study of 285 hospital survivors of myocardial infarction. In these patients both the QRS score and ejection fraction were measured by radionuclide ventriculography at discharge. The correlation between ejection fraction and QRS score was weak. In 22 patients who died during six to 12 months follow up the ability of the ejection fraction and QRS score to predict mortality was assessed in terms of sensitivity, specificity, predictive value of a positive and negative test, and efficiency. For ejection fraction $<40 \%$ and a QRS score $\geqslant 6$ sensitivity was respectively $73 \%$ and $64 \%$, specificity $73 \%$ and $56 \%$, predictive value of a positive test $18 \%$ and $11 \%$, predictive value of a negative test $97 \%$ and $95 \%$, and efficiency $73 \%$ and $56 \%$.

Both ejection fraction and QRS score may be used to identify patients at low and high risk during one year follow up, but, contrary to initial expectations, the QRS score appears to be of little value in estimating ejection fraction and is less accurate than ejection fraction in predicting late survival in hospital survivors of myocardial infarction.

The 12 lead electrocardiogram is widely used to diagnose and follow up patients after myocardial infarction. It is inexpensive and non-invasive and therefore easily repeatable. Since the direct measurement of left ventricular function has been shown to be a major determinant of prognosis in such patients, ${ }^{1}$ the recent introduction by Wagner et al, ${ }^{2}$ Ideker et al, ${ }^{3}$ and Roark et $a l^{4}$ of a weighted QRS score which showed a good correlation with infarct size and left ventricular ejection fraction 56 has attracted considerable interest. ${ }^{7-9}$ Furthermore, the QRS score was shown to be useful for predicting hospital as well as late mortality afer myocardial infarction. ${ }^{6-10}$ These optimistic expectations from the original studies have been tempered by some subsequent reports ${ }^{7-9}$ which found a weak correlation between Wagner's QRS score and

Requests for reprints to Dr Paolo Fioretti, Erasmus University, Thoraxcenter, Dr Molewaterplein 40, 3015 GD Rotterdam, The Netherlands.

Accepted for publication 3 October 1984 left ventricular ejection fraction. Young et al 9 found an even weaker correlation between ejection fraction and other electrocardiographic scores such as described by Askenazi et al, ${ }^{11}$ Gottwik et $a l, 12$ and Rautaharju et al. ${ }^{13}$ In the light of this controversy, the value of the QRS score described by Wagner et $a^{2}$ was prospectively reassessed for determining left ventricular ejection fraction and predicting late survival in $\mathbf{2 8 5}$ hospital survivors of myocardial infarction.

\section{Patients and methods}

Two hundred and eighty seven hospital survivors of acute myocardial infarction who were admitted to a coronary care unit between 1 March 1981 and 31 January 1983 formed the data base for this study. During this period there were 422 potential candidates (hospital survivors of acute myocardial infarction); 57 were excluded because the electrocardiographic score could not be computed (nine had complete left bundle branch block, 20 complete right 
Table 1 Explanation of $Q R S$ scoring system ${ }^{2}$

\begin{tabular}{|c|c|c|c|c|c|}
\hline $\begin{array}{l}\text { ECG } \\
\text { lead }\end{array}$ & $\begin{array}{l}\text { Q wave } \\
\text { duration } \\
\text { (ms) }\end{array}$ & $\begin{array}{l}R \text { wave } \\
\text { duration } \\
\text { (ms) }\end{array}$ & $\begin{array}{l}\text { Amplimude } \\
\text { ratios }\end{array}$ & Points & Maximum \\
\hline \multirow{2}{*}{ I } & $\geqslant 30$ & - & $\sqrt{0}-1$ & 1 & - \\
\hline & $\bar{x}_{10}$ & - & $R: Q \leqslant 1$ & i & 2 \\
\hline \multirow[t]{2}{*}{ II } & $\begin{array}{l}\geqslant 40 \\
\geqslant 30\end{array}$ & $\bar{z}$ & $=$ & 2 & $\frac{1}{2}$ \\
\hline & $\geqslant 30$ & - & & 1 & 2 \\
\hline \multirow{2}{*}{ aVL } & $=$ & - & $R: Q \leqslant 1$ & 1 & 2 \\
\hline & $\begin{array}{l}\geqslant 00 \\
\geqslant 40\end{array}$ & E & - & 3 & - \\
\hline \multirow[t]{4}{*}{ aVF } & $\geqslant 30$ & - & - & 1 & 二 \\
\hline & - & - & $R: Q \leqslant 1$ & 2 & 二 \\
\hline & $\overline{-}$ & - & $R: Q \leqslant 2$ & 1 & 5 \\
\hline & Any & $=50$ & - & 1 & - \\
\hline \multirow[t]{3}{*}{ V1 } & - & $\geqslant 40$ & $\overline{-}$ & $\begin{array}{l}2 \\
1\end{array}$ & $\bar{z}$ \\
\hline & - & - & $R: Q \geqslant 1$ & 1 & 4 \\
\hline & Any or & $\leqslant 20$ & - & 1 & - \\
\hline \multirow[t]{3}{*}{ V2 } & & $\begin{array}{l}\geqslant 60 \\
\geqslant 50\end{array}$ & - & 2 & - \\
\hline & & - & $\mathbf{R}: S \geqslant 1.5$ & 1 & $\overline{4}$ \\
\hline & Any or & $\leqslant 30$ & - & 1 & 1 \\
\hline V3 & $\geqslant 20$ & - & & 1 & - \\
\hline \multirow[t]{2}{*}{ V4 } & E & 二 & $\begin{array}{l}R: Q \text { or } R: S \leq 0.5 \\
R: Q\end{array}$ & 2 & -5 \\
\hline & $\geqslant 30$ & - & - & 1 & 2 \\
\hline \multirow[t]{3}{*}{ V5 } & - & - & $\mathbf{R}: \mathbf{Q}$ or $\mathbf{R}: S \leqslant 1$ & 2 & - \\
\hline & & - & $\mathbf{R}: \mathbf{Q}$ or $\mathbf{R}: S \leqslant 3$ & 1 & 3 \\
\hline & $\geqslant 30$ & - & & 1 & - \\
\hline \multirow{2}{*}{ V6 } & - & - & $\mathbf{R}: \mathbf{Q}$ or $\mathbf{R}: S \leqslant 1$ & 2 & - \\
\hline & & - & $R: Q$ or $R: S \leqslant 3$ & 1 & 3 \\
\hline
\end{tabular}

bundle branch block, 21 left superior fascicular block, five left inferior fascicular block, two pre-excitation, and two ventricular hypertrophy) and 78 were excluded because the ejection fraction measurement was unavailable. Myocardial infarction was diagnosed on the basis of at least two of the following conditions: typical history, classic electrocardiographic signs, and a diagnostic increase in serum enzyme activity.

For this group of $\mathbf{2 8 5}$ patients, the mean age was $\mathbf{5 7}$ (range 22-82) years, $82 \%$ were male, and $27 \%$ had a previous myocardial infarction. On admission 37\% had an acute anterior myocardial infarction, $38 \%$ an inferior-posterior myocardial infarction, and $25 \%$ non- $Q$ wave myocardial infarction; $74 \%$ were in Killip clinical class I. The median hospital stay was 13 (range 7-58) days.

To determine the QRS score, standard 12 lead electrocardiograms were obtained on a three channel Hewlett Packard 1513 A automatic cardiograph recorder at a paper speed of $25 \mathrm{~mm} / \mathrm{s}$ on the day of hospital discharge or one day before. Conventional speed and sensitivity were used, because they are advocated for current clinical use. The QRS scoring system as described by Wagner $e t a l^{2}$ was applied (Table 1). The calculations were validated by the independent measurement of the score from a random sample of 39 electrocardiograms by the original author of the score, who was blinded to our measurements; the independent measurements showed no significant difference from the study readings (study score mean (SD) 4.8 (3.8) vs independent score 5.4 (3.9)). The correlation coefficient was 0.94 (SEE 1.3) with no apparent bias introduced.

Radionuclide ventriculography was performed at discharge in the $45^{\circ}$ left anterior oblique view after in vivo labelling of the red blood cells with $555 \mathrm{MBq}$ (15 mCi) of technetium-99 m. Acquistion was performed during a six minute period with a Searly Phogamma V camera (Siemens cardiac camera) equipped with a low energy all purpose-collimator.

The data were processed by a computer program with automated contour detection and correction for background activity. Left ventricular ejection fraction was computed from the end systolic and end diastolic images, as previously described. ${ }^{14}$

After hospital discharge all patients were followed at regular intervals. The median follow up was 10 (range 6-14) months. Mortality was the endpoint of interest in this study.

STATISTICAL ANALYSIS

Univariate analysis with Student's $t$ test, $\chi^{2}$ test, Fisher's exact-test, or linear regression analysis were applied when appropriate. The most advantageous cutoff values to predict mortality were selected from visual inspection of the receiver-operator characteristic curves (ROC). ${ }^{15}$ In these curves the specificity and sensitivity of the test are plotted, where sensitivity is 


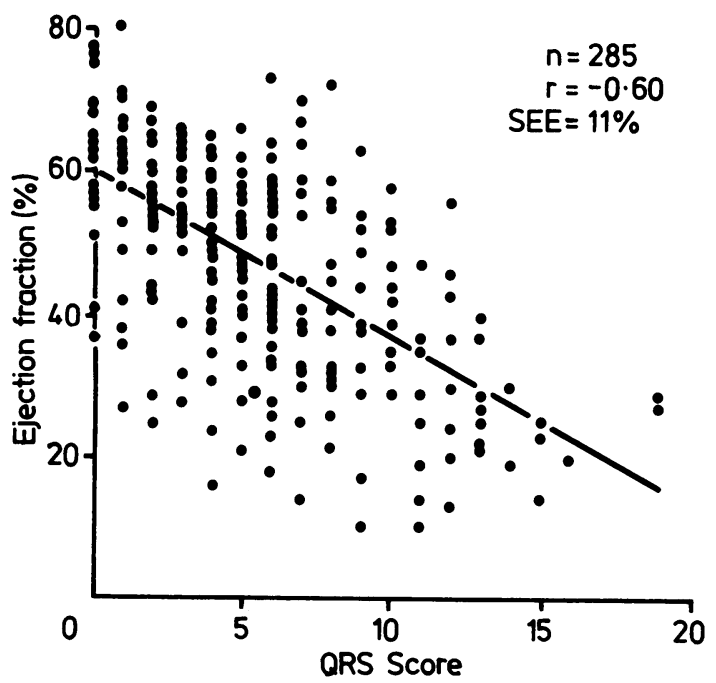

Fig. 1 Correlation between radionuclide ejection fraction and QRS score.

the fraction of correct classification of patients who satisfy the "endpoint" criteria, and specificity the fraction of correct classification of all patients who satisfy the "non-endpoint" criteria. These curves, when generated for different tests, provide a direct comparison of the various test results over the entire range of measurements. After selection of the most advantageous cutoff point for ejection fraction and the QRS score their relative accuracy to predict death was also determined in terms of predictive value of a positive test (true positives/all positive tests), predictive value of a negative test (true negative/all negative tests), and efficiency (true positives + true negatives/ total population).

\section{Results}

Radionuclide ventriculograms and the QRS score were available in 285 patients. The correlation coefficient between the ejection fraction and $Q R S$ score in the entire group was -0.60 (SEE (standard error of the estimates) 11\%) (Fig. 1). When patients with first infarction $(n=202)$ are considered separately from those with previous infarction $(n=83)$ the correlation was slightly stronger in the former group $(r=-0.61$ vs $r=-0.48)$, but the dispersion of the data was just as large in the two groups (SEE 11\%). The correlation between the ejection fraction and QRS score in patients with first anterior transmural infarction $(r=-0.56)$ was similar to that in patients with first inferior infarction $(r=-0.43)$ (Fig. 2) because of the equally large SEE (10\%). Of 285 patients, there were 263 late survivors. Their ejection fraction was

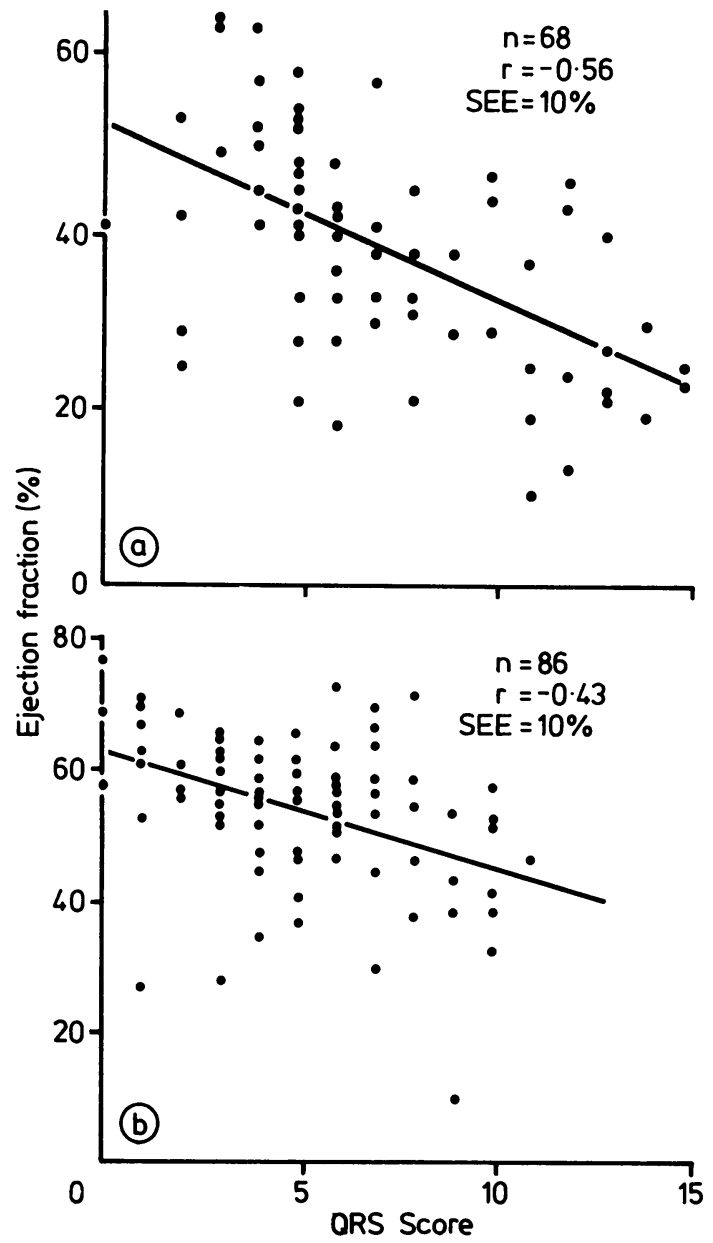

Fig. 2 Correlation between radionuclide ejection fraction and $Q R S$ score in patients with (a) fust anterior infarction and (b) frist inferior infarction.

higher $(48(14) \%$ vs $35(16) \%, \mathrm{p}<0.001)$ and $\mathrm{QRS}$ score lower $(5.4(3.7)$ vs $7 \cdot 0(4 \cdot 1), \mathrm{p}=0.05)$ than in the 22 non-survivors. The visual inspection of the receiveroperator characteristic curves from radionuclide ventriculography and QRS score (Fig. 3) indicate that the ejection fraction had a superior predictive accuracy than the QRS score for late mortality. The "best" cutoff points - that is, the points with the highest sensitivity and the highest specificity-were $40 \%$ for ejection fraction and six for the QRS score. Survival and the other indices measuring the accuracy of the test to predict mortality by ejection fraction, QRS score, and the two tests combined are shown in Tables 2 and 3. They all indicate the superior accuracy of ejection fraction compared with the QRS score. The predictive accuracy was not improved by combining the 


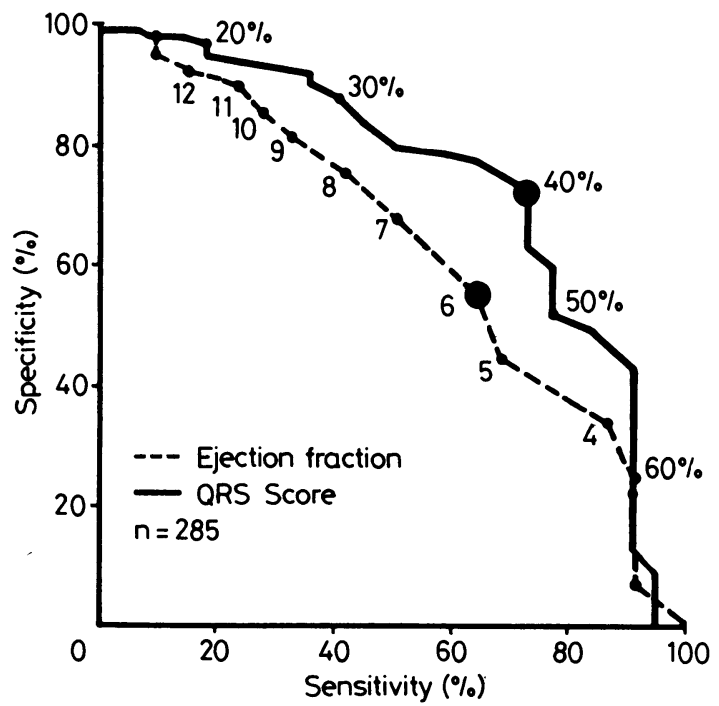

Fig. 3 Receiver-operator characteristic curves of ejection fraction and $Q R S$ score for prediction of late mortality. During the entire range of measurements ejection fraction had a higher sensitivity than $Q R S$ score at comparable specificity to predict late mortality. The "best" cutoff points-that is, those with the highest sensitivity for the highest specificity-were $40 \%$ for ejection fraction and 6 for $Q R S$ score.

ejection fraction and the QRS score, which, when compared with the ejection fraction alone, decreased the sensitivity while the other indices of predictive accuracy were unchanged.

\section{Discussion}

Several electrocardiographic indices have been reported to correlate with left ventricular function. ${ }^{211-1316}$ Nevertheless, in contrast to initial expectations based on small series of patients, ${ }^{35}$ Young et al found in their review ${ }^{9}$ that the correlation coefficient between ejection fraction and QRS score according to Wagner et $a l^{2}$ was rather low $(\mathrm{r}=0.60)$. Because óther authors also had similarly disappointing results, ${ }^{7-9}$ they questioned the clinical usefulness of the QRS score for estimating ejection fraction in
Table 3 Indices of accuracy in predicting late mortality from radionuclide ejection fraction $(E F)$ and $Q R S(S C)$ score in 285 patients. Figures are percentages

\begin{tabular}{llll}
\hline & $E F<40 \%$ & $S C \geqslant 6$ & $\begin{array}{l}E F<40 \% \text { and } \\
S C \geqslant 6\end{array}$ \\
\hline Sensitivity & 73 & 64 & 54 \\
$\begin{array}{l}\text { Specificity } \\
\text { Predictive value of a }\end{array}$ & 73 & 56 & 78 \\
$\begin{array}{l}\text { positive test } \\
\text { Predictive value of a }\end{array}$ & 18 & 11 & 17 \\
$\quad$ negative test & 97 & 95 & 95 \\
Efficiency & 73 & 56 & 76 \\
High risk group & 31 & 46 & 24 \\
\hline
\end{tabular}

individual patients. We assessed the value of Wagner's score to estimate radionuclide left ventricular ejection fraction in a larger population as part of a continuing prospective study of patients after myocardial infarction. Our results corroborate those of Young et al ${ }^{9}$ and de Pace et al, ${ }^{7}$ who found a weak correlation between ejection fraction and QRS score in such patients (Table 4).

Since it has been suggested that the QRS score is more accurate for subgroups of patients ${ }^{59}$ we separately examined patients with a first transmural anterior and inferior infarction (Figs. 2 and 3). Since these results are based on a much larger number of patients than reported by previous authors, they confirm that the QRS score is unable accurately to predict the ejection fraction in individual patients.

Since the electrocardiogram is a standard method that is universally available and inexpensive it still seemed worthwhile to assess its predictive value for late mortality after hospital discharge even if we found that the QRS score correlated rather weakly with ejection fraction. Hindman et $\mathbf{a l}^{\mathbf{6}}$ recently delineated high and low risk groups of patients after myocardial infarction by the use of Wagner's QRS score. As expected, in our series patients who died had a higher QRS score than survivors $(7 \cdot 0(4 \cdot 1)$ vs 5.4(3.7), $\mathrm{p}=0.05)$ and ejection fraction was lower $(35(16) \%$ vs $48(14) \%, p<0.0001)$, suggesting more extensive myocardial damage. The accuracy of the QRS score to predict mortality was, however, lower than that of the ejection fraction (Fig. 3, Table 3). The most advan-

Table 2 Late survival in 285 patients in whom the $Q R S$ score $(S C)$ and radionuclide ejection fraction (EF) was measured. Figures are numbers of patients

\begin{tabular}{|c|c|c|c|c|c|}
\hline & \multicolumn{2}{|c|}{ QRS score } & \multicolumn{2}{|c|}{ Ejection fraction } & \multirow{2}{*}{$\begin{array}{l}E F<40 \% \text { and } \\
S C \geqslant 6\end{array}$} \\
\hline & $\geqslant 6$ & $<6$ & $<40 \%$ & $\geqslant 40 \%$ & \\
\hline $\begin{array}{l}\text { Non-survivors } \\
\text { Survivors } \\
\text { Total } \\
\text { Mortality }\end{array}$ & $\begin{array}{r}14 \\
116 \\
130 \\
11\end{array}$ & $\begin{array}{r}8 \\
147 \\
155 \\
5\end{array}$ & $\begin{array}{l}16 \\
72 \\
88 \\
18\end{array}$ & $\begin{array}{r}6 \\
191 \\
197 \\
3\end{array}$ & $\begin{array}{l}12 \\
57 \\
69 \\
17\end{array}$ \\
\hline
\end{tabular}


Table 4 Correlation of left ventricular ejection fraction and Wagner's QRS score

\begin{tabular}{|c|c|c|c|c|}
\hline & No of patients & Correlation coefficient & $S E E(\%)$ & Regression equation \\
\hline $\begin{array}{l}\text { Present study } \\
\text { Palmeri et al } \\
\text { Young et } \text { al }^{9} \\
\text { Seino et } \text { al }^{8} \\
\text { de Pace et } a l^{7} \\
\text { Roubin et al }{ }^{10}\end{array}$ & $\begin{array}{r}285 \\
55 \\
172 \\
32 \\
41 \\
181\end{array}$ & $\begin{array}{l}-0.60 \\
-0.88 \\
-0.60 \\
-0.72 \\
-0.61 \\
-0.81\end{array}$ & $\begin{array}{l}12 \\
6 \\
? \\
? \\
? \\
12\end{array}$ & $\begin{array}{l}\mathrm{EF}=60-2.3 \times \mathrm{QRS} \text { score } \\
\mathrm{EF}=59-3.0 \times \mathrm{QRS} \text { score } \\
\mathrm{EF}=59-2.3 \times \mathrm{QRS} \text { score } \\
\mathrm{EF}=59-2.1 \times \mathrm{QRS} \text { scor } \\
\mathrm{EF}=59-2.0 \times \mathrm{QRS} \text { score } \\
\mathrm{EF}=66-3.3 \times \mathrm{QRS} \text { score }\end{array}$ \\
\hline
\end{tabular}

SEE, standard error of the estimate.

tageous cutoff points for the two individual tests were $40 \%$ for ejection fraction and 6 for the QRS score.

Identification of patients at high and low risk was thus possible with both the QRS score and the ejection fraction. Although the predictive value of a positive test (ejection fraction $<\mathbf{4 0 \%}$ or QRS score $\geqslant 6$ ) was rather low for both tests, it was slightly better for ejection fraction: $18 \%$ of patients with an ejection fraction $<40 \%$ died as did $11 \%$ with a QRS score $\geqslant 6$. Such a low predictive accuracy for late death is not surprising because of the low incidence of mortality ( $7 \%$ in the present series). This means that only a very sensitive test is a good predictor of mortality, whereas the prediction of survival should be easier. In fact low risk patients could be identified by both methods with high accuracy (Table 3) since $97 \%$ of patients with ejection fraction $>40 \%$ and $95 \%$ of those with a $Q R S$ score $<6$ were late survivors. Nevertheless, the efficiency of radionuclide ejection fraction remained superior to that of the QRS score (73\% vs $56 \%$ ). The combination of the worst outcome of the two tests (ejection fraction $<40 \%$ and $Q R S$ score $\geqslant 6$ ) did not provide a better prediction of mortality (Tables 2 and 3 ). In fact, even if the high risk group was slightly smaller compared with that defined by ejection fraction alone (24\% vs $31 \%)$ the sensitivity was much lower $(54 \%$ vs $73 \%)$.

We thank A Beelan, T Baardman, $\mathrm{H}$ Wolf, and $\mathrm{H} \mathrm{J}$ ten Katen, who assisted in the establishment of the data bank used in this study, $\mathrm{K}$ van Duyvendijk, who performed most of the nuclear studies, and $\mathrm{N} \mathrm{B}$ Hindman, Duke University, Durham, USA, who computed the QRS score of a random sample of our patients.

\section{References}

1 The Multicenter Postinfarction Research group. Risk stratification and survival after myocardial infarction. $N$ Engl f Med 1983; 309: 331-6.

2 Wagner GS, Freye CJ, Palmeri ST, et al. Evaluation of a QRS scoring system for estimating myocardial infarct size. I. Specificity and observer agreement. Circulation 1982; 65: 342-7.

3 Ideker RE, Wagner GS, Ruth WK, et al. Evaluation of a QRS scoring system for estimating myocardial size. II. Correlation with quantitative anatomic findings for anterior infarcts. Am $\mathcal{F}$ Cardiol 1982; 49: 1604-14.

4 Roark SF, Ideker RE, Wagner GS, et al. Evaluation of a QRS scoring system for estimating myocardial infarct size. III. Correlation with quantitative anatomic findings for inferior infarcts. Am 7 Cardiol 1983; 51: 382-9.

5 Palmeri ST, Harrison DG, Cobb FR, et al. A QRS scoring system for assessing left ventricular function after myocardial infarction. $N$ Engl f Med 1982; 306: 4-9.

6 Hindman NB, Tina DA, Anderson I, et al. Correlation of electrocardiographic and isoenzymatic estimations of myocardial infarct size. [Abstract]. $\mathcal{F}$ Am Coll Cardiol 1983; 1: 705.

7 DePace NL, Iskandrian AS, Hakki A, Kane SA, Segal BL. Use of QRS scoring and thallium-201 scintigraphy to assess left ventricular function after myocardial infarction. Am $\mathcal{F}$ Cardiol 1982; 50: 1262-8.

8 Seino Y, Staniloff HM, Shell WE, Mickle D, Shah PK, Vyden JK. Evaluation of a QRS scoring system in acute myocardial infarction: relation to infarct size, early stage left ventricular ejection fraction, and exercise performance. Am $\mathcal{F}$ Cardiol 1983; 52: 37-42.

9 Young SG, Abouantoun S, Savvides M, Madsen EB, Froelicher V. Limitations of electrocardiographic scoring systems for estimations of left ventricular function. $\mathcal{F} \mathrm{Am}$ Coll Cardiol 1983; 1: 1479-88.

10 Roubin GS, Shen WF, Kelly DT, Harris PJ. The QRS scoring system for estimating myocardial infarct size: clinical, angiographic and prognostic correlations. $f \mathrm{Am}$ Coll Cardiol 1983; 2: 38-44.

11 Askenazi J, Parisi AF, Cohn PF, Freedman WB, Braunwald E. Value of the QRS complex in assessing left ventricular ejection fraction. Am $\mathcal{f}$ Cardiol 1978; 41: 494-9.

12 Gottwik MG, Parisi AF, Askenazi J, McCaughan D. Computerized orthogonal electrocardiogram: relation of QRS forces to left ventricular ejection fraction. Am $\mathcal{J}$ Cardiol 1978; 41: 9-13.

13 Rautaharju PM, Warren JW, Jain U, Wolf HK, Nielsen CL. Cardiac infarction injury score: an electrocardiographic coding scheme for ischemic heart disease. Circulation 1981; 64: 249-56.

14 Reiber JHC, Lie SP, Simoons ML, et al. Clinical validation of fully automated computation of ejection fraction from gated equilibrium blood pool scintigrams. $f$ Nucl Med 1983; 24: 1099-1107.

$15 \mathrm{McNeil}$ BJ, Keeler E, Adelstein SJ. Primer on certain elements of medical decision making. $N$ Engl $\mathcal{f}$ Med 1975; 293: 211-5.

16 Luwaert RJ, Cosyns J, Rousseau MF, Brassuer LA, Detry JM, Brohet CR. Reassessment of the relation between QRS forces of the orthogonal electrocardiogram and left ventricular ejection fraction. Eur Heart $\mathcal{F}$ 1983; 4: 103-9. 